\title{
A Política Municipal de Inclusão de Crianças com Deficiência na Educação Infantil no Município de Dourados, MS.
}

\author{
The municipal policy of inclusion of children with disability \\ on early chidhood education in Dourados, MS
}

\author{
Natacya Munarini Otero' \\ Marilda Moraes Garcia Bruno²
}

\section{Resumo \\ Este trabalho teve por objetivo conhecer a formulação de políticas públicas de educação especial e o seu impacto sobre a prática educativa para a inclusão de crianças com deficiência nos Centros de Educação Infantil do Município de Dourados, MS. Para tanto, buscou-se confrontar os documentos nacionais e locais, as Leis, Diretrizes e Resoluções para a implementação da educação inclusiva. Utilizou-se da entrevista semi-estruturada com gestores da política central e escolar para compreender a cultura institucional e, a percepção dos gestores sobre as políticas públicas de educação inclusiva; conhecer como as diretrizes, normas, programas e projetos políticos pedagógicos são elaborados; quais as representações sociais, fundamentos e práticas}

utilizadas na elaboração e implementação da política de inclusão. Essas análises permitiram apontar alguns caminhos para a inclusão: a necessidade de maior articulação entre os diferentes níveis de gestão educacional; efetivação do atendimento educacional especializado em turno contrário ao escolar; o apoio pedagógico especializado deve se efetivar com o trabalho articulado entre a equipe de educação especialensino regular e, não com a retirada da criança da sala de aula para estimulação paralela; incentivar a participação de professores e pais na elaboração do projeto político pedagógico e nas tomadas de decisões sobre a modificação da escola.

Palavras Chave: Políticas Públicas, educação infantil, práticas de inclusão. 


\section{Abstract}

This study aimed to ascertain the formulation of public policies of special education and its impact on educational practice for the inclusion of disabled children in Child Education Centers of the city Dourados, MS. Therefore, it sought to confront the national and local papers, the laws, resolutions and guidelines for the implementation of inclusive education. It was used the semistructured interview with managers of the policy central and school to understand the institutional culture and the manager's perception about the public policies of inclusive education, to know how the guidelines, standards, educational programs and political projects are developed, which are the social representations, principles and practices used in the preparation and implementation of the inclusion policy. These analyses have allowed to point some paths for the inclusion: the need for greater coordination between the different levels of educational administration, educational settlement care specialized in period against to the school; the pedagogical specialist support must be done with work articulated between the work team of special education-regular, and not with the removal of children from the classroom to stimulation parallel; encourage the teachers' participation and parents in preparing the political educational project and decisionmaking about the modification of the school.

Key Words: Public Policies, Early Childhood Education, Inclusion Practices. 


\section{Introdução}

As políticas públicas estão constantemente mudando à medida em que são formadas e reformadas, modificadas e transformadas [...] Ela tem que ser inferida a partir da série de ações e comportamentos intencionais de muitas agências e funcionários governamentais responsáveis pela sua implementação ao longo do tempo (PALUMBO, 1994, p. 35).

Ao longo dos anos, principalmente a partir da Declaração dos Direitos Humanos em 1948, e depois no Brasil, após a adesão à Constituição Federal (1988) em vigor, tornou-se lugar comum o discurso que dissemina a democratização e o acesso das minorias à Educação.

A construção histórica da educação de pessoas com deficiência no Brasil está pautada sobre 0 atendimento de forma segregada, em instituições especializadas na assistência, tratamento e no ensino. Assim, as questões relativas à Educação Especial nem sempre foram discutidas em âmbito Nacional, concentrandose até os anos de 1960, em iniciativas mais localizadas no âmbito escolar, restritas apenas às instituições especializadas (FERREIRA, 2006, p. 86 e 87).

A partir do final dos anos 1960, e de modo mais destacado nos anos de 1970, que as reformas educacionais alcançaram a área de educação especial sob a égide dos discursos danormalizaçãoe daintegração[...] o contexto da época apresentava atuação preponderante das instituições especializadas, quer em termos de atendimento, quer em termos de influência na formulação de políticas setoriais do Estado (idem, p. 87 e 88).

Segundo Mazzotta (2003, p. 27), o surgimento da educação especial na política educacional brasileira vem ocorrer somente no final dos anos cinqüenta e início da década de sessenta do século $X X$. O autor divide esse momento da história em dois períodos: de 1854 a 1956, em que as iniciativas não eram oficiais $e$, as particulares isoladas, o que denuncia não haver no Brasil uma política nacional de atendimento às pessoas com deficiência. Num segundo, que vai de 1957 a 1993, o atendimento educacional aos excepcionais foi explicitamente assumido, em nível nacional, pelo governo federal, com a criação de Campanhas especificamente voltadas para este fim (MAZZOTTA, 2003, p. 49).
Nesse sentido, é notável que a construção da política de educação especial no Brasil é recente. A elaboração de Leis, das Normas e Regulamentos como função de governo, assumida de forma descentralizada pelos administradores estaduais, são ações de agendas governamentais a partir da política nacional de integração de pessoas com deficiência na década de 1980.

Observa-se que as pressões internacionais para que o Brasil implementasse os princípios da Declaração dos Direitos Humanos (1948) e a reivindicação dos movimentos sociais para a garantia dos Direitos das pessoas com deficiência, são fatores que exerceram forte e importante influência para a criação de políticas educacionais para pessoas com deficiência.

Assim, a expansão da educação pública e gratuita às pessoas com deficiência sob a responsabilidade das secretarias de educação e de serviços públicos de educação especial, ocorreu após a Constituição Federal e o Estatuto da Criança e Adolescente ECA, Lei n. 8069, 1990. Atendimento previsto também em instituições de ensino privado.

A defesa dos direitos humanos, tendência mundial das políticas públicas para a inclusão social e educacional, tem assegurado o direito aos alunos com deficiência aprenderem desde cedo nos Centros de Educação Infantil e participarem plenamente da vida social e cultural de suas comunidades.

A Constituição Federal de 1988, afirma: "a educação, direito de todos e dever do Estado e da família, visando ao pleno desenvolvimento da pessoa, seu preparo para o exercício da cidadania e sua qualificação para o trabalho" (Art. 205), estipula como dever do Estado a oferta do atendimento educacional especializado, preferencialmente na rede regular de ensino (Art. 208).

A Lei de Diretrizes e Bases da Educação Nacional n. 9.394/96-LDB/96 avançou na elaboração do texto quanto aos direitos sociais, direito à diversidade, garantia de acesso e permanência com qualidade e atendimento às necessidades educacionais especiais. Essas premissas estão presentes no Art. 58, quando afirma: "Haverá, quando necessário, serviços de apoio especializado, na escola regular, para atender às peculiaridades da clientela 
de educação especial". E, Art. 59 quando se refere aos sistemas de ensino, seu currículo, métodos, recursos, formação profissional, acesso, estrutura.

A respeito da Educação Especial, em parágrafo único, a legislação afirma: "O Poder Público adotará, como alternativa preferencial, a ampliação do atendimento aos educandos com necessidades especiais na própria rede pública regular de ensino, independentemente do apoio às instituições previstas neste artigo" (LDB/96). Observa-se, então, pela primeira vez, na Legislação educacional brasileira, a ênfase na expansão da oferta de educação especial e a inclusão de crianças com deficiência na rede regular de ensino.

Dessa forma, a ampliação de matrículas na educação infantil, a formação inicial e continuada dos professores para o atendimento às necessidades educacionais especiais; padrões mínimos de infra-estrutura na escola, com disponibilização de recursos didáticos especializados e de apoio à aprendizagem dessas crianças, são questões relevantes, que vêm sendo asseguradas desde o Plano Nacional de Educação - PNE, Lein. 10.172/2001. Constata-se, nesse sentido, que tais questões mantêm-se pertinentes até hoje.

Com isso é possível notar que tanto as Diretrizes e Bases da Educação Nacional como - Plano Nacional de Educação transferem à escola toda a responsabilidade pela operacionalização da proposta de inclusão.

O sistema educacional brasileiro, na última década, vem paulatinamente avançando em relação à formulação de políticas publicas inclusivas. Nesse sentido, as Diretrizes Nacionais de Educação Especial para a Educação Básica, Resolução CNECEB n. 2/2001, recomendaram a inclusão de crianças pequenas nos Centros de Educação Infantil, enfatizando ainda a necessidade do atendimento educacional especializado, entretanto, admitiram a permanência de escolas especiais para crianças com deficiência mental e ou sensorial.

A nova proposta de reestruturação dos sistemas de ensino para que atendam a todos os alunos, sem exceção ou qualquer forma de categorização por níveis ou graus de deficiência, denomina-se Política Nacional de Educação Especial na Perspectiva da Educação Inclusiva (MEC, 2008). Essa prática política tem como objetivos o acesso, a participação e a aprendizagem de alunos com deficiência, transtornos globais de desenvolvimento, altas habilidades ou superdotação nas escolas regulares. Orienta os sistemas de ensino para atenderem às necessidades educacionais especiais, de forma que garantam:

- Transversalidade da educação especial desde a educação infantil até a educação superior;

- Atendimento educacional especializado;

- Continuidade da escolarização a níveis mais elevados de ensino;

- Formação de professores para o atendimento educacional especializado;

- Formação dos professores do ensino regular para a educação inclusiva;

- Acessibilidade urbanística, arquitetônica, nos mobiliários e equipamentos, nos transportes, na comunicação e informação;

- Participação da família e comunidade;

- Articulação intersetorial para a implementação das políticas públicas.

Esses objetivos já se faziam presentes nas Diretrizes Nacionais de Educação Especial para a educação básica (2001), no entanto, a novidade diz respeito ao rompimento com a estrutura paralela e segregada de educação especial. A política avança quando propõe a transversalidade com as mesmas oportunidades de aprendizagem para todos os educandos e, não admite a existência de escolas ou classes especiais por categorias ou a oferta de educação segregada a qualquer tipo de deficiência.

Pesquisadores na área de políticas públicas educacionais como Mainardes (2006), Palumbo (1994) e Ball e Bowe (1992), discutem que o foco de análise das políticas públicas, deveria incidir sobre a formação do discurso da política e sobre a interpretação ativa que os profissionais que atuam no contexto da prática fazem para relacionar os textos da política à prática. Essa tarefa envolve, na opinião dos autores, identificar os processos de resistência, acomodações, subterfúgios e conformismos dentro e entre as arenas da prática.

Para esses autores a política é construída 
em ciclo contínuo, composta por três contextos principais: o da influência, o da produção do texto e o da prática. Esses contextos estão interrelacionados, não são lineares e apresentam arenas, lugares e grupos de interesse e cada um deles envolve disputas e embates.

Assim, a proposta deste trabalho foi estudar a construção das políticas públicas de inclusão de crianças com deficiência nos Centros de Educação Infantil de Dourados, MS, analisar o contexto de influência e a produção de textos como Planos de Governo, Leis, Diretrizes, programas; e verificar os possíveis resultados no contexto da prática educacional no cotidiano dos CEIMs.

\section{Desenvolvimento do Estudo}

Este estudo fundamentou-se no princípio de que as políticas públicas são ações complexas invisíveis, em constante modificação e transformação. A política, conforme Palumbo (1994, p. 35), "é um processo, uma série histórica de interações, ações e comportamentos de muitos participantes". A proposta política na visão do autor, não pode ser observada, tocada ou sentida.

Ball (1998) propõe que as políticas deveriam ser analisadas em termos de seus impactos nas relações e nas interações com as desigualdades existentes. Os efeitos gerais da política tornamse evidentes quando aspectos específicos de mudanças e um conjunto de respostas são observados na prática.

Por esse caminho buscamos conhecer e analisar o texto, contexto da elaboração das políticas; verificar quais as crenças, conceitos e opiniões dos operadores da política por meio da prática. Assim, participaram desta pesquisa gestores da Coordenadoria da Educação Infantil e da Coordenadoria de Educação Especial, funcionários efetivos da Secretaria Municipal de Educação de Dourados, MS, denominados neste estudo (G1) e (G2); os gestores de Centros de Educação Infantil, denominados (GC). O critério para a escolha dos gestores de Centros de Educação Infantil foi o número de crianças com deficiência matriculadas nas salas regulares.

O estudo caracteriza-se como pesquisa qualitativa com análise documental e entrevistas como orienta Lakatos (2001). Para a coleta de dados foi elaborado um roteiro de entrevista semi-estruturada, contendo questões com os seguintes objetivos: compreender a percepção dos gestores sobre as políticas públicas de educação inclusiva; conhecer os impactos das Diretrizes Nacionais de Educação Especial sobre a política local; conhecer a cultura institucional e como são elaboradas e implementadas as diretrizes e normas do Município de Dourados, MS; identificar as representações sociais, os fundamentos e práticas de inclusão construídas pela gestão municipal e escolar.

Assim, as entrevistas foram realizadas por meio de gravação em fita cassete, em espaço escolhido pelos entrevistados. Utilizou-se a técnica de situação dialógica e espontânea; após a entrevista, realizou-se a escuta e transcrição dos depoimentos gravados e a análise do conteúdo das comunicações conforme orienta Bardin (1977).

\section{Resultados e Discussão}

Para análise dos documentos e ações recorremos à definição de política pública proposta por Palumbo (1994), em que o autor define política como o princípio orientador por trás de regulamentos, leis e programas, sua manifestação visível é a estratégia adotada pelo governo para solucionar os problemas públicos (PALUMBO, 1994, p. 38).

\section{Análise da Política Municipal}

No âmbito Municipal foi encontrado o esboço de um documento mimeografado (sem título e data), o qual relata que a política de atenção educacional aos alunos com necessidades associadas ou não, tem se modificado ao longo do processo histórico de transformação social. Informa que a partir de 2001 foi constituída uma equipe no âmbito da Secretaria Municipal de Educação para implementar as políticas de educação especial no Município de Dourados MS.

O texto refere-se a uma parte do Plano Municipal de Educação, ainda não aprovado, porém que enfatiza os princípios relativos aos documentos orientadores no âmbito Internacional e da Legislação Brasileira. Além disso, traz um histórico sobre a evolução do 
atendimento às crianças com necessidades educacionais, por meio de dados registrados em tabelas, citando também as modificações ocorridas com o aumento de matrículas nas escolas urbanas, rurais e indígenas.

O mesmo realça que o sistema municipal de educação investe na formação de profissionais objetivando capacitá-los para o atendimento desse alunado no ensino fundamental. Propõe como metas: o atendimento, a garantia da qualidade do ensino, o respeito às diferenças considerando as potencialidades e necessidades de cada um. Orienta a escola a propiciar um ambiente com adequações necessárias no espaço físico, acesso ao currículo, adaptações nos procedimentos didáticos e nas atividades avaliativas.

De acordo com o Censo Escolar (INEP, 2007) na rede municipal de Dourados, há apenas três crianças com deficiência matriculadas em creches e 11 em pré-escolas. Já na rede particular (Escolas Especiais) há oito crianças em creches e 73 crianças matriculadas em pré-escolas. Esses dados indicam que as recomendações de ampliação de matrícula do Plano Nacional (2001) e o Compromisso de Educação Para Todos (2006) não foram concretizadas.

O único documento vigente, a Deliberação do Conselho Municipal de Educação 028/2006, dispõe sobre o Funcionamento da Educação Básica no Sistema Municipal de Ensino, determina que a modalidade de Educação Especial na etapa do ensino fundamental terá regulamentação própria. A referida deliberação orienta que o Projeto Político Pedagógico e o Regimento Escolar devam contemplar as reais necessidades educativas dos alunos atendidos, orienta "a organização da instituição para o atendimento aos educandos com necessidades educacionais especiais tanto no espaço fisco, respeitando a Lei de Acessibilidade, quanto nas orientações pedagógicas e no processo de avaliação dos mesmos" (COMED, 2006, art.24). Há referência à redução de até cinco alunos por turma quando houver aluno com necessidade educacional especial, conforme critérios a serem definidos pela Coordenadoria de Educação Especial.

Aquestão derecursoshumanoseinvestimentos financeiros não foram contemplados nos documentos encontrados. Saviani (2007) discute que além da formação de professores, a qualidade da educação vai depender "do aspecto financeiro, da base infra-estrutural, das condições de trabalho e de salário dos professores". Nesse contexto, o Plano Municipal e o Plano de Desenvolvimento da Educação, comentado anteriormente, deveriam prever financiamento para a educação infantil e para o atendimento educacional especializado.

Para tanto, vale recorrer à Cury (2007) quando afirma que "as políticas públicas sem recurso se tornam declaratórias e potencialmente inócuas", ao passo que tornando-se inofensivas e sem grandes danos, são também inválidas.

No Brasil também é necessário que haja um financiamento que abarque e sustente o que está sendo planejado, estudado e discutido. Para isso é preciso rever como estão sendo elaboradas as Políticas Públicas da Educação, e desvendar como a Educação Especial vem sendo contemplada na agenda financeira das escolas e Secretaria Municipal de Educação.

O financiamento da educação escolar representa uma clara intervenção do poder público em uma área que se define como um direito da cidadania (CURY, 2007). Nesse sentido, o autor afirma que, por ser direito público subjetivo, o poder público, face ao ensino obrigatório, não pode deixar de atender a todo o universo escolarizável.

\section{O autor continua:}

O titular deste direito é qualquer pessoa (grifos do autor), de qualquer idade, que não tenha tido acesso à escolaridade obrigatória [...] Na prática, isso significa que qualquer criança ou adulto que não tenha entrado no ensino fundamental pode exigi-lo e 0 juiz deve deferir imediatamente, obrigando as autoridades constituídas a cumpri-lo. (idem).

Após ter claro que o deveré do Estado, concluise que ele é o principal responsável para que se efetivem as políticas públicas de educação. Dentro desse contexto vale lembrar-nos do PDE - Plano de Desenvolvimento da Educação, que, apesar de não consistir em um Plano, no real significado da palavra, abriga praticamente todos os programas em desenvolvimento pelo MEC, agregando 30 ações sobre as mais variadas áreas da Educação (SAVIANI, 2007).

Conforme Saviani (2007), o PDE representa um importante passo no enfrentamento do 
problema da qualidade da educação básica, mas, em sua configuração atual, ainda não nos dá garantia de sua efetivação com êxito. Seu êxito será resultado de um trabalho pedagógico desenvolvido seriamente, próprio de profissionais bem preparados e que acreditam na relevância do papel que desempenham na sociedade, sendo remunerados à altura de sua importância social.

Nesse âmbito do PDE o MEC acaba de anunciar O BPC na escola, trata-se de um Programa deacompanhamento emonitoramento de acesso e permanência na escola dos beneficiários com deficiência, de 0 -18 anos, a ser desenvolvido em ação interministerial entre os Ministérios da Educação, Desenvolvimento Social e Combate à Fome, Saúde e Secretaria Especial de Direitos Humanos. As ações não foram ainda clarificadas.

\section{Análise do discurso dos gestores}

As informações coletadas nas entrevistas foram agrupadas nos seguintes temas:

\section{O impacto da política nacional sobre a política municipal de inclusão}

Os Gestores da Secretaria Municipal de Educação de Dourados relataram que procuram implementar políticas de educação especial a partir de 2001, com algumas dificuldades:

"As diretrizes nacionais de inclusão não estão sendo $100 \%$ contempladas, mas vejo que em nível municipal nós temos nos esforçado [...] "(G1).

"Eu vejo que essa tendência de inclusão mundial é uma coisa que chega tarde, nós estamos atrasados, a gente tem muita coisa pela frente pra fazer, pra implantar e implementar." (G2).

"Nós temos, além de todo o plano nacional e estadual o Plano Municipal de Educação que já foi entregue à Câmara dos vereadores para aprovação". (G1).

Os discursos confirmam a ausência de Diretrizes políticas e Normas específicas que regulem 0 atendimento educacional especializado e a inclusão de alunos com deficiência no ensino regular. Observa-se ainda a falta de articulação e integração entre os níveis responsáveis pela implementação da política:

"[...] a gente quase não tem acesso à documentação, nós temos que saber qual é o direito que a criança tem, se agente não tem mais crianças nos CEIMs é porque a mãe não tem conhecimento daquela lei." (G.C).

A Promotora de Justiça Patrícia Albino Galvão Pontes (2008) discute a impossibilidade dos pais optarem por escolas especiais, pois constitui-se em violação dos direitos humanos fundamentais.

\section{A Prática de inclusão de alunos com necessidades educacionais especiais.}

Os relatos das Gestoras indicam que a inclusão de crianças se efetiva a partir da matrícula e do preenchimento da ficha elaborada pela Educação Especial.

As falas indicam que o Projeto Político Pedagógico está em processo de construção:

"nós já temos um capítulo, no projeto político pedagógico, que fala sobre a inclusão, que garante a criança dentro do CEIM [...] tanto na parte física, como na parte material, como na questão metodológica, na questão profissional [...]" (G2).

"Eu vejo que a parte teórica, o discurso está muito bonito, mas falta muita preparação dos profissionais para que realmente a inclusão aconteça dentro do sistema educacional." (GC).

"Temos que preparar melhor os profissionais [...] necessitamos de maiores recursos para poder preparar não só os profissionais como o espaço de atendimento" (G.1).

"Temos também o trabalho de complementação e suplementação, se há um aluno surdo você tem o interprete, se é um aluno cego você tem o braile" (G2).

A Política Nacional de Educação Especial na perspectiva da educação inclusiva (2008) é clara quanto a necessidade do atendimento às necessidades educacionais especiais no contexto da sala de aula, é ao que se refere a gestora, presença de intérprete, uso do sistema braile para comunicação. No entanto, esse fragmento de fala revela a ausência do atendimento educacional especializado no outro turno escolar como recomenda a política.

"A dificuldade é que nós não temos ainda todo o espaço adaptado. A maior dificuldade é com o deficiente visual, estamos tentando nos adaptar, trabalhamos com jogos; eles trabalham normal na sala e depois tem uma hora, que a gente faz um trabalho diferenciado com 
jogos diretamente com a criança, com jogos e brincadeiras, somente o professor de apoio faz isso" (GE). Observa-se aqui o atendimento paralelo e descontextualizado.

Os discursos apontam para a falta de recursos humanos, físicos e recursos pedagógicos adequados às especificidades das crianças com deficiência e que venham atender as necessidades educacionais especiais, garantidas na política nacional.

Soraia Napoleão (2008, p. 24) pondera sobre a necessidade de repensar a organização escolar nos níveis macro e micro estruturais, contemplando desde a gestão no sentido mais amplo do "sistema de ensino" e da escola, até a organização da prática educacional em sala de aula.

Nessa perspectiva, Bruno (2007) defende $\mathrm{o}$ atendimento educacional especializado, em outro turno, com programas de intervenção precoce centradas na família [...] mediante ação compartilhada entre os serviços de educação especial e os Centros de Educação Infantil.

"Hoje nós temos 14 intérpretes na rede municipal de ensino que atuam com alunos surdos, temos intérprete na reserva indígena, é uma experiência única no Brasil” (G2).

A gestora pontua a inédita e louvável iniciativa de formar intérpretes para a educação escolar indígena tendo em vista o acesso à comunicação e ao bilingüismo, assegurados pela legislação vigente. No entanto, não há referência sobre o atendimento educacional especializado para a instrução de LIBRAS e a construção da linguagem para educandos surdos indígenas e não indígenas.

As falas dos diferentes gestores não indicam a participação dos pais e professores na elaboração do projeto político pedagógico, em planos de inclusãooutomada de decisões acerca da educação de crianças com necessidades educacionais especiais. A Gestora Escolar revela que a participação dos pais se dá em relação à resolução de problemas que surgem no cotidiano "levar crianças ao médico e por meio da colaboração nos eventos sociais".

\section{A formação dos professores}

Os discursos apontam que há formação continuadaparaosprofessoressobretemasgerais de educação e para o educar na diversidade. As informações dos diferentes gestores apontam a formação específica em educação especial para os professores simpáticos à causa da inclusão, capacitados em serviço.

Segundo Freitas (2006, p. 169) a formação do professor de modo geral (educador especial ou educador da classe comum) deve incluir programas/ conteúdos que desenvolvam competências de um profissional intelectual para atuar em situações singulares. Assim pressupõe-se que o desenvolvimento das habilidades profissionais sejam sempre contínuas e permanentes no processo de desenvolvimento dos professores.

"A Secretaria Municipal de Educação, somos hoje Pólo de abrangência para 20 municípios no Programa Educar na Diversidade (MEC). A formação continuada é realizada com recursos próprios do município, através de encontros, seminários, cursos de libras, de braile." (G2).

"A gente não tem grupos de estudos no CEIM, o que existe é o repasse, por exemplo, a professora vai lá, na SEMED e faz uma formação, vem e faz o repasse para os colegas." (GE).

Nesse sentido vale ressaltar a divisão feita por Freitas (2006, p. 171), com base em Bueno (1998), envolvendo dois tipos de formação profissional:

1. dos professores do ensino regular, com vistas a um mínimo de formação, já que a expectativa é da inclusão dos alunos com "necessidades educativas especiais";

2. dos professores especializados nas diferentes "necessidades educativas especiais", quer seja para 0 atendimento direto a essa população, quer seja para 0 apoio ao trabalho realizado por professores de classes regulares que integrem esses alunos (apud BUENO, 1998, p. 7).

Com base nessa perspectiva as falas das gestoras não contemplam a efetiva formação continuada dos professores, uma vez que ela não é oferecida de forma geral transformando a escola regular em uma escola inclusiva, com práticas inclusivas, e sim a um número de profissionais simpáticos à inclusão.

Além disso, Mainardes (2006) justifica a importância da participação de agentes do governo e professores na implementação das políticas públicas, ao afirmar:

[...] os professores e demais profissionais exercem um papel ativo no processo de interpretação e reinterpretação 
das políticas educacionais e, dessa forma, 0 que eles pensam e no que acreditam têm implicações para 0 processo de implementação das políticas (p. 53).

\section{Considerações Finais}

O estudo dos documentos nacionais e locais, a análise dos discursos do gestor da política Municipal de Educação Infantil, do gestor da Educação Especial e de Gestores dos Centros de Educação Infantil da cidade de Dourados/MS permitiram compreender como são elaboradas as políticas públicas de inclusão de crianças com deficiência, analisar o contexto de influência e verificar os impactos e os resultados no contexto da prática educacional no cotidiano dos CEIMs.

Os participantes do estudo revelaram em seus relatos um esforço da SEMED no sentido de garantir o direito social de acesso de crianças com deficiência nos Centros de Educação Infantil. No entanto, evidenciou-se a ausência de normas, diretrizes e orientações pedagógicas que pudesse regular ou subsidiar o processo de inclusão desses alunos na educação infantil.

Os avanços apontados pelos gestores dizem respeito ao investimento em cursos de capacitação, intérprete de LIBRAS, intérprete para alunos surdos nas aldeias; e o Braile para as crianças cegas.

As dificuldades apontadas para a implementação de uma prática pedagógica inclusiva foram: capacitação centralizada, pouco acesso aos textos, leis e documentos; falta de recursos financeiros para adequação de espaço, recursos específicos e pedagógicos especiais. Essas questões esbarram no impacto das políticas públicas nacionais quanto ao financiamento para a educação especial e na limitação dos recursos financeiros para a educação infantil.

O impacto da Política Nacional de Educação na perspectiva da Educação Inclusiva se faz parcialmente presente na Deliberação do Conselho Municipal de Educação 028/2006 que dispõe sobre o Funcionamento da Educação Básica no Sistema Municipal de Ensino, determina que a modalidade de Educação Especial na etapa do ensino fundamental terá regulamentação própria. A referida deliberação orienta que o Projeto Político Pedagógico e o Regimento Escolar devem contemplar as reais necessidades educativas dos alunos atendidos, orienta "a organização da instituição para o atendimento aos educandos com necessidades educacionais especiais tanto no espaço físico, respeitando a Lei de Acessibilidade, quanto nas orientações pedagógicas e no processo de avaliação dos mesmos". Não faz referência à oferta do atendimento educacional especializado e silencia-se quanto ao atendimento educacional em escolas especiais.

Para a compreensão desse processo destacamos as ponderações de Palumbo (1994, p. 41) quando retrata a importância do estudo das políticas públicas:

A política pública permite que compreendamos quem recebe os benefícios da atividade governamental e como. Finalmente, o estudo da política pública nos capacita a determinar 0 quão bem os ideais de democracia são mantidos em uma sociedade complexa tão dependente de burocracias públicas.

O gestor da Educação Especial fez referência à parceria com as Universidades: UEMS para capacitação de intérpretes de LIBRAS e mais recentemente com a UFGD para formação continuada de profissionais de alguns CEIMs.

A análise documental e dos discursos dos gestores permitiram apontar alguns caminhos para a inclusão: a necessidade de maior articulação entre os diferentes níveis de gestão educacional; efetivação do atendimento educacional especializado em turno contrário ao escolar; o apoio pedagógico especializado deve se efetivar com o trabalho articulado entre a equipe de educação especial-ensino regular $e$, não com a retirada da criança da sala de aula para estimulação paralela; incentivar a participação de professores e pais na elaboração do projeto político pedagógico e nas tomadas de decisões sobre a modificação da escola. Por fim, para a efetivação das políticas públicas se faz necessário: investimentos, Planos de Desenvolvimento Educacional e formação continuada do professor no espaço escolar.

A conclusão deste estudo nos remete à reflexão de Certeau (2005, p. 214) na qual a política não garante a felicidade nem confere significado às coisas. Ela cria ou recusa condições de possibilidades. Interdita ou permite: torna possível ou impossível. E sob esse viés que ela se apresenta aqui, no sentido de que a ação cultural choca-se com as interdições silenciosamente postas pelos poderes. 


\section{Referências Bibliográficas}

BALL, S. J. Diretrizes políticas globais, consumo e política educacional. In SILVA L. H. A escola cidadãno contexto da globalização. Petrópolis: Vozes, 1998.

BARDIN, L. Análise de Conteúdo. Lisboa: Edições 70, 1977.

BRASIL, MEC, Secretaria da Educação Especial. Política Nacional de Educação especial na perspectiva da Educação Inclusiva. Revista de Educação Especial. Brasília: SEESP/MEC, 2008.

BRASIL, INEP. Censo Escolar 2007. Disponível em: http/www.inep.gov.br/http; acesso em: 10/04/2008.

BRASIL, MEC, Secretaria da Educação Especial. Diretrizes Nacionais para a Educação Especial na Educação Básica. Brasília: CNE/CEB, 2001.

Lei de Diretrizes e Bases da Educação Nacional. Brasília: MEC/SEESP, 1996.

Constituição (1988). Constituição da República Federativa do Brasil. Brasília, DF: Senado, 1998.

BRUNO, M. M. G. Saberes e Práticas da Inclusão na educação infantil. BRASIL/MEC/SEESP, Brasília, 2003, vol. 1,4 e 8 .

CERTEAU, M. A cultura no Plural. Campinas: Papirus, 2005.

CURY. C. R. J. Estado e políticas de financiamento em educação. Revista Educação e Sociedade. Campinas: Cedes, vol. 28, n. 10, 2007.

FERREIRA, J. R. Educação especial, inclusão e política educacional: notas brasileiras. In: RODRIGUES, D. Inclusão e Educação: Doze olhares sobre a educação inclusiva. São Paulo: Summus, 2006.

FREITAS, S. N. A formação de professores na educação inclusiva: construindo a base de todo o processo. In: RODRIGUES, D. Inclusão e Educação: Doze olhares sobre a educação inclusiva. São Paulo: Summus, 2006.

FREITAS, S. N. e OSÓRIO, A. C. do N. O currículo em grades: mais um desafio para a Educação Inclusiva. In: Ensaios Pedagógicos Programa Educação Inclusiva: direito à diversidade. Brasília: Ministério da Educação, Secretaria de Educação Especial, 2007.

LAKATOS, E. M. e MARCONI, M. de A. Fundamentos de metodologia científica. São Paulo: Atlas, 2001.

MAINARDES, J. Abordagem do ciclo de políticas: uma contribuição para a análise de políticas educacionais. Campinas: CEDES, v. 27, n. 94, p. 47-69, 2006.

MAZZOTTA, M. J. S. Educação Especial no Brasil: História e Políticas Públicas. $\quad$ São Paulo: Cortez, 1996.

MITTLER, P. Educação inclusiva: contextos sociais. Porto Alegre: Artmed, 2003.

PALUMBO, D. J. A abordagem de política pública para o desenvolvimento político na América. In: Política de capacitação dos profissionais da educação. Belo Horizonte: FAE/IRHJP, 1989. p. 35-61.

SAVIANI, D. O plano de desenvolvimento da educação. Revista Educação e Sociedade, Campinas: CEDES, v. 28, n. 100. Especial, p. 641-1274, 2007.

SECRETARIA MUNICIPAL DE EDUCAÇÃO DE DOURADOS. Plano Municipal de Educação. (mimeografado, sem data, doc. não aprovado).

Dourados, MS.

Deliberação COMED n. 028, de 05 de Dezembro de 2006. Diário Oficial, Ano VIII n. 1928. 